\title{
Gero-Psychiatric Problems: An Analytical Study
}

\author{
C. Venkata Subbaiah*, Dr. Challa Venkata Suresh**, Dr. Y.Nagendra Rao ***
}

\begin{abstract}
The study was planned to analyze the gero-psychiatric problems among elderly who were attending an out patient psychiatric department. The case details were collected from the hospital records $(O P)$ and were analyzed to examine the nature of gero-psychiatric problems in $60+$ persons. Most frequently reported complaints were analysed in terms of socio-economic profiles of the elderly.
\end{abstract}

\section{Introduction}

The elderly are subjected to multiple morbidity; like physical, mental and social among others. The genesis could be from biochemical and morphological changes in the ageing brain and other organs, diminished immunity and not too favorable psycho socioeconomic milieu. According to the research report by Rao and Madhavan (1983) the overall prevalence rate of psychiatric morbidity increased from $71.5 \%$ for those over 60 (but below 70) to 124 for those in the 70s and 155 in those over 80 (Rao \& Madhavan, 1983). When projected, it yields a figure of nearly 4 million for India. Among the most frequently reported gero-psychiatric problems are depression; Mood disorders; late onset Schizophrenia; Alcoholic dependency etc., (Rao, 2004). Geriatric medicine relating to psychiatry is yet to be well recognized as a sub-specialty in many developing countries including India (Ramamurti, 2004; Rao, 2004). The study was planned with the following objective:

- To analyze the gero-psychiatric problems among elderly who were attending an out patient psychiatric department.

\section{Sample\& Methodolgy:}

The total sample consists of 121 elderly male and female from the age groups of 60-65, 66-70, 71-75 and $75+$ age groups. Of these $56 \%$ belong to rural areas and $44 \%$ belong to urban areas. Majority of the subjects $(63 \%)$ are having formal education and most of them belong to lower economic groups. The living arrangement of the sample clearly shows that $74 \%$ of the samples are living with their families.

Table - I: Socio-Demographic Details of the Sample

\begin{tabular}{|c|c|c|c|c|c|}
\hline \multirow{2}{*}{ Sl. No. } & \multirow{2}{*}{ Categories } & \multicolumn{2}{|c|}{ Male } & \multicolumn{2}{|c|}{ Female } \\
\hline & & $\mathbf{F}$ & $\%$ & $\mathbf{F}$ & $\%$ \\
\hline \multirow[t]{5}{*}{1} & \multicolumn{5}{|l|}{ Age groups } \\
\hline & $60-65$ & 37 & 52.1 & 32 & 64 \\
\hline & $66-70$ & 16 & 22.5 & 10 & 20 \\
\hline & $71-75$ & 10 & 14.1 & 04 & 8 \\
\hline & $76+$ & 08 & 11.3 & 04 & 8 \\
\hline \multirow[t]{3}{*}{2} & \multicolumn{5}{|l|}{ Locality } \\
\hline & Urban & 36 & 50.7 & 19 & 38 \\
\hline & Rural & 35 & 49.3 & 31 & 62 \\
\hline \multirow[t]{3}{*}{3} & \multicolumn{5}{|l|}{ Educational status } \\
\hline & Without formal education & 23 & 32.4 & 20 & 40 \\
\hline & Literate & 48 & 67.6 & 30 & 60 \\
\hline \multirow[t]{3}{*}{4} & \multicolumn{5}{|l|}{ Economic status } \\
\hline & Upper middle class & 31 & 42.3 & 23 & 46 \\
\hline & Lower class & 40 & 56.3 & 27 & 54 \\
\hline \multirow[t]{3}{*}{5} & \multicolumn{5}{|l|}{ Living Arrangemalets } \\
\hline & With family & 57 & 80.3 & 36 & 72 \\
\hline & Institutionalized & 13 & 18.3 & 04 & 8 \\
\hline
\end{tabular}

The data for the present study was compiled from the psychiatric out patient hospital records of Sri Ramachandra Medical College and Research Institute, Chennai. The OP psychiatric Department case records from $1^{\text {st }}$ January to $31^{\text {st }}$ December, 2005 were analysed to examine the nature of gero-psychiatric problems in the aged men and women (i.e., subjects those of 60 years and above). After collecting the data the most frequently reported complaints were analysed in terms of socio-economic profiles of the elderly. Firstly, the data on Geropsychiatric problems reported by the total sample was analyzed. 
Table - II : Geropsychiatric Problems Reported in the Total Sample

\begin{tabular}{|c|l|c|c|c|c|}
\hline \multirow{2}{*}{ Sl. No. } & \multicolumn{1}{|c|}{ Problems } & \multicolumn{2}{|c|}{ Male } & \multicolumn{2}{c|}{ Female } \\
\cline { 3 - 6 } & & F & $\%$ & F & $\%$ \\
\hline 1. & Organic M.D. & 17 & 24.3 & 07 & 14 \\
\hline 2. & Late Schizophrenia & 10 & 14.1 & 12 & 24 \\
\hline 3. & Mood disorders & 23 & 32.4 & 19 & 38 \\
\hline 4. & Neurotic and Stress & 12 & 17 & 8 & 16 \\
\hline 5. & Alcoholic dependency & 5 & 7 & - & - \\
\hline 6. & Others disorders & 4 & 5.6 & 4 & 8 \\
\hline
\end{tabular}

Table - II showing data on Geropsychiatric problems reported by older male and female. Among these more organic mental disorders are reported by older men $(24.3 \%)$ compared to older women (14\%). Late onset of schizophrenia and other psychotic disorder are more in female (24 percent) compared to male (14 percent).

Mood (affective) disorders are equal in both males and females (around $38 \%$.) Neurotic and stress related sometization disorders are similar in both groups (nearly 16\%) and specifically alcoholic dependence is found in male elderly only. Other disorders (sleep, Nephrological syndrome, etc.) were highly reported by female ( 8 percent) than male.

Table - III : Gero-psychiatric Problems in Different Age Groups

\begin{tabular}{|c|c|c|c|c|c|c|c|c|c|c|c|c|c|c|c|c|}
\hline \multirow{2}{*}{$\begin{array}{c}\text { Gero psychiatric } \\
\text { problems }\end{array}$} & \multicolumn{4}{|c|}{$60-65$} & \multicolumn{4}{|c|}{$66-70$} & \multicolumn{4}{|c|}{$71-75$} & \multicolumn{4}{|c|}{$76+$} \\
\hline & $\mathrm{M}$ & $\%$ & $\mathrm{~F}$ & $\%$ & $\mathrm{M}$ & $\%$ & $\mathrm{~F}$ & $\%$ & $\mathrm{M}$ & $\%$ & $\mathrm{~F}$ & $\%$ & $\mathrm{M}$ & $\%$ & $\mathrm{~F}$ & $\%$ \\
\hline Organic M.D. & 07 & 9.86 & 04 & 8 & 04 & 5.6 & 02 & 4 & 04 & 56 & 01 & 2 & 02 & 2.82 & - & - \\
\hline $\begin{array}{l}\text { Late } \\
\text { Schizophrenia }\end{array}$ & 0.2 & 2.82 & 08 & 16 & 04 & 5.6 & 01 & 2 & 04 & 5.6 & 02 & 4 & 0 & & 01 & 2 \\
\hline Mood disorders & 17 & 24 & 12 & 24 & 03 & 4.2 & 03 & 6 & 02 & 2.82 & 01 & 2 & 01 & 1.41 & 03 & 6 \\
\hline $\begin{array}{l}\text { Neurotic and } \\
\text { Stress }\end{array}$ & 05 & 7.04 & 06 & 12 & 03 & 4.2 & 02 & 4 & - & - & - & - & 04 & 5.6 & - & - \\
\hline $\begin{array}{l}\text { Alcoholic } \\
\text { dependency }\end{array}$ & 03 & 4.22 & - & & 01 & 1.41 & - & & - & - & - & - & 1 & 1.14 & - & - \\
\hline Others disorders & 03 & 4.22 & 03 & 6 & - & 0 & 01 & 2 & 1 & 1.41 & - & - & - & - & - & - \\
\hline
\end{tabular}

Results in table Table-III show that organic M.D., late schizophrenia, mood disorders and neurotic stress were reported to be high in 60-65, followed by 66-70 group compared to 71-75 and 77.

Table - IV : Gero-psychiatric Problems Reported by Different Economic Groups

\begin{tabular}{|l|c|c|c|c|c|c|c|c|}
\hline \multirow{2}{*}{$\begin{array}{c}\text { Gero } \\
\text { Psychiatric problems }\end{array}$} & \multicolumn{4}{|c|}{ Upper Middle Class } & \multicolumn{4}{c|}{ Lower Middle Class } \\
\cline { 2 - 10 } & Male & $\%$ & Female & $\%$ & Male & \% & Female & \% \\
\hline Organic M.D. & 6 & 8.45 & 4 & 8 & 10 & 14.1 & 4 & 8 \\
\hline Late Schizhophrenia & 6 & 8.45 & 6 & 12 & 4 & 5.6 & 6 & 12 \\
\hline Mood disorders & 10 & 14.1 & 9 & 18 & 13 & 18.31 & 10 & 20 \\
\hline Neurotic and Stress & 6 & 8.45 & 2 & 4 & 6 & 8.45 & 6 & 12 \\
\hline Alcoholic dependency & 3 & 4.22 & - & - & 2 & 2.82 & - & - \\
\hline Others disorders & 3 & 4.22 & - & - & 2 & 2.82 & 3 & 6 \\
\hline
\end{tabular}

Table-IV showing data on different economic status groups. From the data it is clear that upper middle class people were having less organic M.D. (male 8.45 female 8 percent) than lower middle class people male (14 percent female 8 percent). Males are having more psychiatric problems than females in both the economic classes. But alcoholic dependency is not found in both the groups.

Table-V showing data on psychiatric problems reported by different locality groups. From the data it is clear that both rural and urban elderly reported to have more or less same type of problems. However, mood disorders were more in rural groups and also highly reported by the female group.

Table - V : Gero-psychiatric Problems Reported by different Locality Groups

\begin{tabular}{|l|c|c|c|c|c|c|c|c|}
\hline \multirow{3}{*}{ Gero-psychiatric problems } & \multicolumn{4}{|c|}{ Urban } & \multicolumn{4}{c|}{ Rural } \\
\cline { 2 - 10 } & \multicolumn{2}{|c|}{ Male } & \multicolumn{2}{c|}{ Female } & \multicolumn{3}{c|}{ Male } & \multicolumn{2}{c|}{ Female } \\
\cline { 2 - 10 } & F & $\mathbf{\%}$ & $\mathbf{F}$ & $\mathbf{\%}$ & $\mathbf{F}$ & $\mathbf{\%}$ & F & $\mathbf{\%}$ \\
\hline Organic M.D. & 9 & 12.68 & 4 & 8 & 8 & 11.27 & 3 & 6 \\
\hline Late Schizophrenia & 4 & 5.63 & 6 & 12 & 6 & 8.5 & 6 & 12 \\
\hline Mood disorders & 11 & 15.5 & 8 & 16 & 12 & 17 & 11 & 22 \\
\hline Neurotic and Stress & 8 & 11.27 & 1 & 2 & 4 & 5.63 & 7 & 14 \\
\hline Alcoholic dependency & 3 & 4.22 & - & - & 2 & 2.82 & - & - \\
\hline Others disorders & 1 & 1.41 & 1 & 2 & 3 & 4.22 & 3 & 6 \\
\hline
\end{tabular}


From the data in Table-VI it is clear that geropsychiatric problems were common in the elderly those who are living with the families than those who are living in institutions.

Table - VI: Gero-psychiatric Problems Reported by Different Living Arrangements Groups

\begin{tabular}{|l|c|c|c|c|c|c|c|c|}
\hline \multirow{2}{*}{ Gero-Psychiatric Problems } & \multicolumn{4}{|c|}{ Living with family } & \multicolumn{3}{c|}{ Institutionalized } \\
\cline { 2 - 10 } & Male & $\boldsymbol{\%}$ & Female & $\%$ & Male & \% & Female & $\%$ \\
\hline Organic M.D. & 12 & 17 & 6 & 12 & 5 & 7.04 & 1 & 2 \\
\hline Late Schizhophrenia & 10 & 14.1 & 9 & 18 & 2 & 2.82 & 2 & 4 \\
\hline Mood disorders & 18 & 25.35 & 19 & 38 & 4 & 5.63 & 1 & 2 \\
\hline Neurotic and Stress & 11 & 12.5 & 8 & 16 & 1 & 1.41 & 0 & \\
\hline Alcoholic dependency & 5 & 7.04 & - & & - & - & - & - \\
\hline Others disorders & 4 & 5.63 & 3 & 6 & - & - & 1 & 2 \\
\hline
\end{tabular}

From the above discussion it is evident that the percent of elderly who are attending the psychiatric wards are increasing. From the above trends it is also clear that among all the geropsychiatric problems mood disorders were reported to be high followed by late Schizophrenia. Therefore, it is high time to plan mental health interventions particularly for the elderly who are living in rural areas, economically poor and also those who are living in the families. 